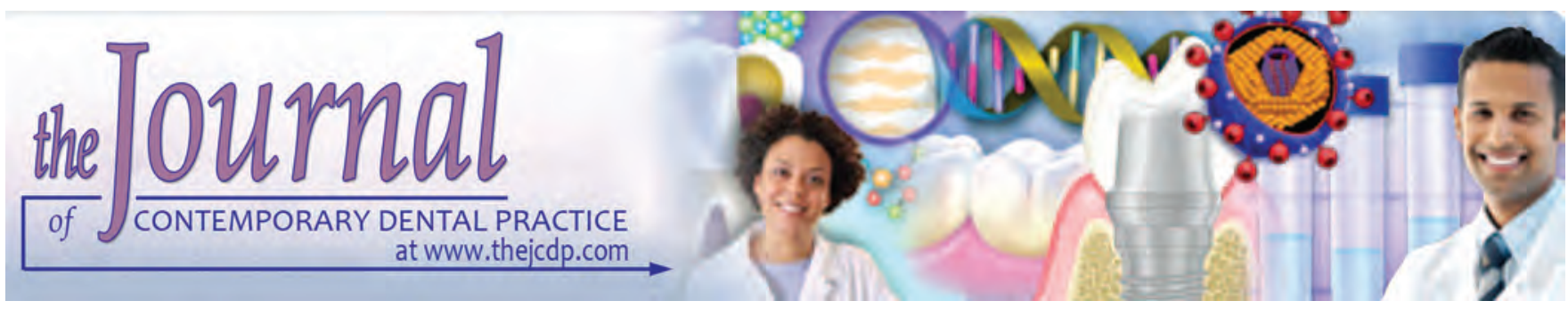

\title{
Evaluation of the Antifungal Effect of Chicory Extracts on Candida Glabrata and Candida Krusei in a Laboratory Environment
}

${ }^{1}$ Hosein Eslami, ${ }^{2}$ Hossein Babaei, ${ }^{3}$ Parisa Falsafi, ${ }^{4}$ Mahdi Rahbar, ${ }^{5}$ Fereshteh Najar-Karimi, ${ }^{6}$ Solmaz Pourzare-Mehrbani

\section{ABSTRACT}

Aim: This research has evaluated the extract's antifungal effects on Candida glabrata and Candida krusei in a laboratory environment.

Materials and methods: In this research, to evaluate the antifungal effect and the minimal inhibitory concentration (MIC) determination of chicory extract, the Clinical and Laboratory Standards Institute (CLSI) was used. Candida glabrata and C. krusei funguses were procured from the Tehran Pasteur Institute; they were grown in the relative growing environment according to the required conditions. Also for further assurance about the macrodilution method reality, the agar well diffusion method was used. Finally, the obtained results were analyzed using the Statistical Package for the Social Sciences version 16 software.

Results: The MIC for the chicory extract was $50 \mu \mathrm{g} / \mathrm{mL}$ for $C$. krusei and $100 \mu \mathrm{g} / \mathrm{mL}$ for C. glabrata. On the contrary, in the evaluation of different concentrations of the chicory extract by the agar well diffusion method, $C$. krusei's lack of growth in similar concentrations was greater than that of $C$. glabrata. As a result, the findings related to both the methods of agar well diffusion and MIC prevention concentration maximization proved that $C$. krusei sensitivity to the chicory extract is more compared with the sensitivity of $C$. glabrata.

\footnotetext{
1,3,6 Department of Oral and Maxillofacial Medicine, Dental and Periodontal Research Center, Tabriz University of Medical Sciences, Tabriz, Islamic Republic of Iran

${ }^{2}$ Department of Pharmacology and Toxicology, Tabriz University of Medical Sciences, Tabriz, Islamic Republic of Iran

${ }^{4}$ Department of Operative and Esthetic Dentistry, Faculty of Dentistry, Tabriz University of Medical Science, Tabriz, Islamic Republic of Iran

${ }^{5}$ Private Practice, Tabriz, Islamic Republic of Iran

Corresponding Author: Solmaz Pourzare-Mehrbani, Department of Oral and Maxillofacial Medicine, Dental and Periodontal Research Center, Tabriz University of Medical Sciences, Tabriz Islamic Republic of Iran, Phone: +09148125118, e-mail: Solmaz_pourzare@yahoo.com
}

Conclusion: Chicory extract has the benefits of low price, accessibility, and proper taste as compared with nystatin. It also has fewer side effects, and after a clinical test, it could be considered a proper candidate as an antifungal drug against infections caused by C. krusei and C. glabrata.

Clinical significance: The results obtained from this research have shown that chicory extract has antifungal features and is the best choice as an antifungal drug because of its low price, accessibility, and proper taste as compared with nystatin.

Keywords: Candida, Chicory extract, Fungal infection, Glabrata, Krusei.

How to cite this article: Eslami $\mathrm{H}$, Babaei $\mathrm{H}$, Falsafi $\mathrm{P}$, Rahbar M, Najar-Karimi F, Pourzare-Mehrbani S. Evaluation of the Antifungal Effect of Chicory Extracts on Candida Glabrata and Candida Krusei in a Laboratory Environment. J Contemp Dent Pract 2017;18(11):1014-1020.

Source of support: Nil

Conflict of interest: None

\section{INTRODUCTION}

Oral candidiasis is one of the most prevalent opportunistic fungal infections of the mouth made by a yeast fungal microorganism named candida; approximately $50 \%$ of the population carry this fungus naturally. ${ }^{1}$ Although one of the most common types of candidiasis infection is the albicans type, the widespread use and long-term application of antibiotics, corticosteroids, and immunity-suppressing drugs, as well as underlying diseases such as diabetes, acquired immunodeficiency syndrome (AIDS), etc., have caused the rate of fungal infections to increase; in particular, C. glabrata and C. krusei types have increased more as compared with the past. ${ }^{2,3}$ Furthermore, the infections due to C. glabrata have become more complex, especially in people with an immunity system defection, because of its capability of producing biofilm and an increase of medical resistance to it. ${ }^{4}$ Candida krusei also occurs 
especially in patients of neutropenic, hematologic malignancies and patients receiving bone marrow implants who are resistant toward systemic fungal treatments such as fluconazole and other antifungal treatments. The possibility of living is very low in patients who suffer from fungal infections. ${ }^{5}$ So today, the use of plants and plant compositions is regarded as a potential source for producing new drugs for treating illnesses such as fungal infections. ${ }^{3}$ Chicory extract is obtained from Cichorium intybus, which is one of the Asteraceae plants. It is one of the compositions that has been considered significantly in recent years in medical studies and treatments. ${ }^{6}$ In general, the origin of the chicory plant is in the Western regions, Central Asia, and North Africa. It is widespread in different regions of Iran, especially in the north of Iran, Azerbaijan, and the mountainous areas. This plant usually needs cool weather and a weak sun or some shade, and it cannot tolerate high temperatures. ${ }^{7}$ In the performed studies, the seed, root, and leaves of this plant have effects on the different microorganisms that were evaluated. For many years, this plant has been used for the treatment of AIDS, cancer, sexual incapability, insomnia, and spleen swelling. ${ }^{8}$ Some previous studies proved that $C$. intybus seeds have antioxidant and antimicrobial features. ${ }^{4,9}$

The toxicology studies which were performed on the chicory extract proved the low toxicity of this plant; evaluations made on laboratory mice showed that the chicory root extract in the comestible format of about 70 to $100 \mathrm{mg} / \mathrm{kg} /$ day has no toxic effect. The lethal dose of this drug is more than $2,244 \mathrm{mg} / \mathrm{kg}$ (median lethal dose) in mice, so as a medical treatment, it has no damaging effect. ${ }^{10,11}$ In a study, the chicory extract's anti-inflammation features were evaluated and the important role of chicory in osteoarthritis was clarified. ${ }^{12}$ The antibacterial features of this plant were also realized in different studies. $^{13-16}$

The antibacterial and antioxidation activities of the chicory plant have been proven before, but limited studies were performed on the antifungal features of this plant. In the present research, we have attempted to evaluate the antifungal effects of this extract on C. glabrata and C. krusei in a laboratory environment.

\section{MATERIALS AND METHODS}

\section{Preparing the Fungal Strains}

In this study, the target population was the standard strains of C. glabrata (BSM 11226) and C. krusei (BSM 70079) that were procured from the Tehran Pasteur Institute. These funguses were grown in a fungus dextrose environment at a maximum temperature of $30^{\circ} \mathrm{C}$ for 4 days. The sample volume was determined based on the CLSI.

\section{Chicory Extract Preparation Method}

To prepare the chicory extract, C. intybus leaves were dried according to the standard condition. After being dried completely, the leaves were grained; then, 1,000 gm of grained powder was drenched in a water and ethanol composition for 72 hours. Then, the solvent was passed through a Whatman paper filter; then, with the use of a Heidolph Rotary Evaporator made in Germany, the water was vaporized slowly, and a concentrated liquid was obtained. Then, the liquid was frozen in a freeze dryer (Christ alpha 1-4, Germany) and kept in a freezer below $20^{\circ} \mathrm{C}$ up to the time of use.

\section{Solvent Type Selection}

Based on some previous studies, alcoholic solvents, especially ethanol, has better results compared with acetone. ${ }^{17,18}$ In justification about the solvent type selection, we can declare that the ethanol solvents and methanol could dissolve the nonpolar compositions in the C. intybus plant and reveal the antimicrobial features of the plant more effectively. Usually, compositions such as flavonoids and flavonols, which are of the aromatic type, are dissolved in methanol properly. ${ }^{19,20}$ Under standard condition, it is dried, and after complete drying, 1,000 gm of grained powder is drenched in $70 \%$ water and ethanol solvents for 72 hours. Then, the solvent is passed through a Whatman paper-1 filter, and with the use of a Heidolph Rotary Evaporator (Germany), it is vaporized slowly, and the liquid gets concentrated. Then, the obtained dense liquid is frozen in a freeze dryer (Christ alpha 1-4, Germany) and kept in the freezer at a temperature below $20^{\circ} \mathrm{C}$ up to the time of application.

\section{MIC Determination by the Macrodilution Method}

To evaluate the effect of chicory extract on these funguses and for the determination of the MIC, the macrodilution method was used based on the CLSI protocol.

For this purpose, some amount of fungal colony was taken beside the flame under the ventilator in order to avoid pollution from the saprophytic fungi. We prepared a suspension in a testing pipe containing a sterile physiological serum whose concentration was equal to 0.5 standard of McFarland. Then, to prepare the chicory extract, we dissolved the prepared powder in the ethanol solvent, and based on the CLSI protocol, we prepared different concentrations of the C. intybus for each candida in a total of 20 pipes, and for each of candida, we chose two positive control pipes and two negative controls as the witness, making it a total of 24 pipes. After the suspension was prepared, to avoid vaporization, the testing pipe doors were closed, and we put them inside the incubator for 48 hours at a temperature of $35^{\circ} \mathrm{C}$. After 
48 hours had passed, we evaluated the transparency and opacity of each sample, and for assurance about the fungal growth or lack of growth in each pipe, we cultivated them. It should be noted that this process was performed with a 24-hour strain for both C. krusei and C. glabrata.

\section{Agar Well Diffusion Method}

The agar well diffusion method is widely used for the evaluation of antimicrobe activities in plants or extracts. This method is similar to the disk diffusion method and has simple benefits and low cost. The difference in the agar well diffusion method is that we can prepare adequate and proper space for understanding the material. Furthermore, all antimicrobial and antifungal materials will not fit on the disk. Some disks may be very expensive, or preparing some of them may be really difficult. ${ }^{21}$
In this study, to evaluate the chicory extract's antifungal effect, the agar well diffusion was also used, but for the chicory extract solution, the results obtained from the macrodilution method were documented more. In this method, after preparing a 0.5 concentration of McFarland from the fungal dilution, we reduced the concentration to $1.5 \times 10^{6}$ $\mathrm{CFU} / \mathrm{mL}$, and $500 \mu \mathrm{L}$ of the prepared suspension was transferred to a Mueller-Hinton agar environment and were cultivated by the sterile cotton swab in three directions. Then, wells with a diameter of $6 \mathrm{~mm}$ and an approximate distance of $2.5 \mathrm{~cm}$ were prepared for pipes numbered 2 to 9 according to the chicory extract concentration in the agar level. Then, $100 \mu \mathrm{L}$ of each prepared chicory extract concentration was injected into each well (Figs 1 and 2); then, the plates were incubated for 24 hours at a temperature of $37^{\circ} \mathrm{C}$. Finally, they were evaluated for lack of growth and this action was repeated twice. ${ }^{3,22}$
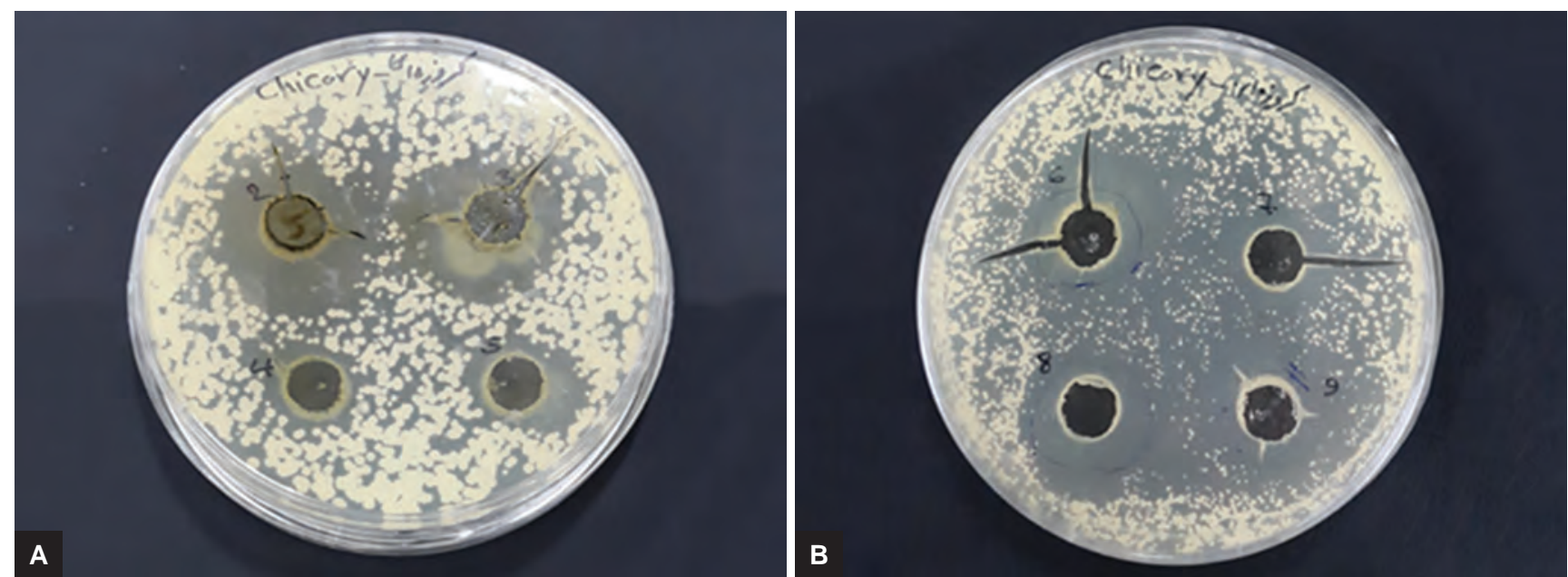

Figs $1 \mathrm{~A}$ and $\mathrm{B}$ : The sample of well diffusion method plates related to $C$. krusei method. (A) Wells number 2 to 5 orderly including concentrations of $1,600,800,400$, and $200 \mu \mathrm{g} / \mathrm{mL}$ of chicory; (B) Wells number 6 to 9 orderly including concentrations of 100, 50, 25 , and $12.5 \mu \mathrm{g} / \mathrm{mL}$ of chicory
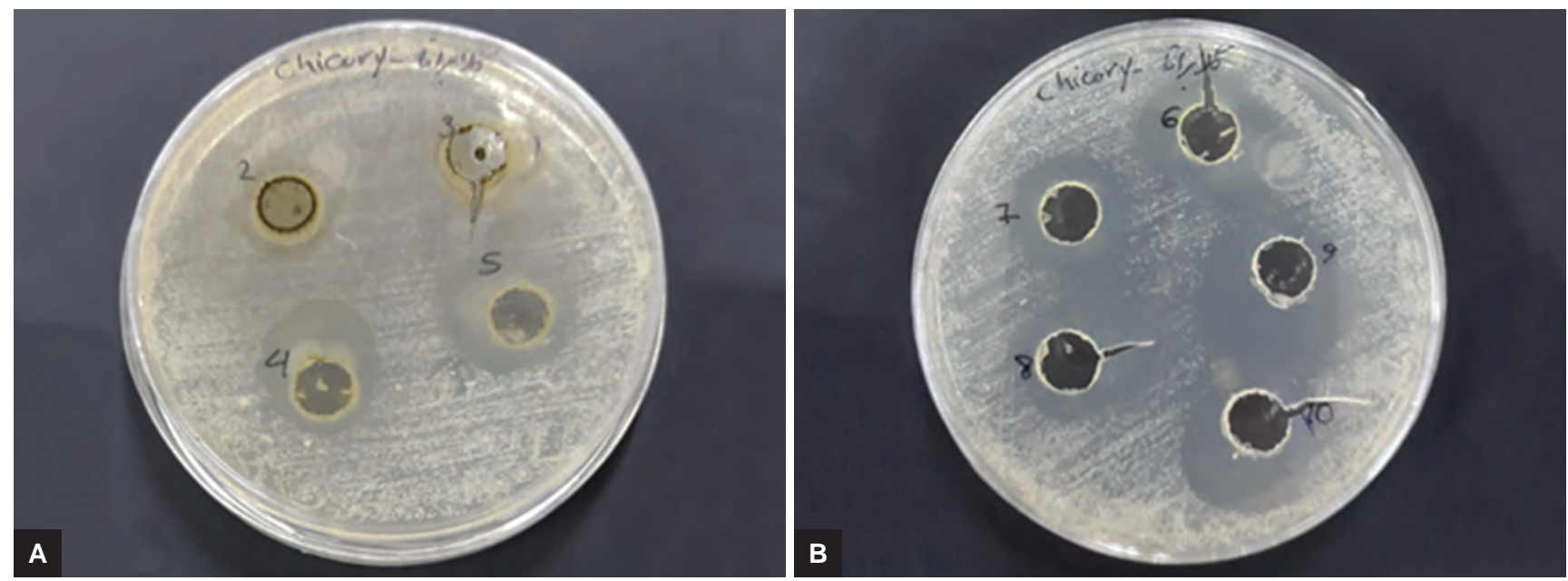

Figs 2A and B: The sample of well diffusion method plates related to $C$. glabrata. (A) Wells number 2 to 5 orderly including concentrations of $1,600,800,400$, and $200 \mu \mathrm{g} / \mathrm{mL}$ of chicory; (B) Wells number 5 to 10 orderly including concentrations of $100,50,25,12.5$, and $6.25 \mu \mathrm{g} / \mathrm{mL}$ of chicory 
Evaluation of the Antifungal Effect of Chicory Extracts

Table 1: The average and standard deviation for halo diameter lack of growth based on the millimeter for chicory extract fungal two-directional analysis of chicory extract in different concentrations

\begin{tabular}{llllllllll}
\hline & \multicolumn{10}{c}{ Chicory concentration $(\mu \mathrm{g} / \mathrm{mL})$} \\
\cline { 2 - 11 } Candida type & 1,600 & 800 & 400 & 200 & 100 & 50 & 25 & 12.5 & 6.25 \\
\hline Candida glabrata & $24 \pm 0.08$ & 20 & $14 \pm 0.14$ & $13 \pm 0.98$ & $12 \pm 0.42$ & $10 \pm 0.84$ & 9 & $8 \pm 0.7$ & $8 \pm 0.8$ \\
Candida krusei & $14 \pm 0.8$ & $13 \pm 0.98$ & $11 \pm 0.84$ & 11 & $11 \pm 0.8$ & 10 & $9 \pm 0.14$ & $8 \pm 0.98$ & $8 \pm 1.41$ \\
\hline
\end{tabular}

Data are reported as mean \pm criterion deviation and the obtained results are outcome of two-time test repetition

Table 2: The results of growth in two types of evaluated candida based on the growth condition in different chicory concentrations

\begin{tabular}{|c|c|c|c|c|c|c|c|c|c|c|}
\hline \multirow[b]{2}{*}{ Candida type } & \multicolumn{10}{|c|}{ Candida growth condition in different chicory concentrations $(\mu \mathrm{g} / \mathrm{mL})$} \\
\hline & 3.12 & 6.25 & 12.5 & 25 & 50 & 100 & 200 & 400 & 800 & 1,600 \\
\hline Candida glabrata & + & + & + & + & - & - & - & - & - & - \\
\hline Candida krusei & + & + & + & + & + & - & - & - & - & - \\
\hline
\end{tabular}

+: Microorganism growth; -: Lack of growth in microorganism

\section{RESULTS}

Based on the results obtained, we can say that C. krusei in concentrations of $100 \mu \mathrm{g} / \mathrm{mL}$ has been stopped (Tables 1 and 2).

According to Tables 1 and 2, chicory extract is $50 \mu \mathrm{g} /$ $\mathrm{mL}$ in C. krusei and it is $100 \mu \mathrm{g} / \mathrm{mL}$ for C. glabrata and this shows more sensitivity on C. krusei compared with chicory extract and in comparison with C. glabrata.

Comparison of the different concentrations of chicory extract by the well diffusion method on C. glabrata and C. krusei with two-way analysis proved that regardless of growth prevention of candida, the halo diameter of $C$. kruse $i$ is greater than that of C. glabrata; so, it demonstrates that C. krusei has more microbial sensitivity to chicory extract, while C. glabrata shows lower sensitivity (Table 3 and Graph 1). The results related to the MIC preventive maximum concentration (Table 1) also approve the above findings.

\section{DISCUSSION}

In this study, the antimicrobial effect of the chicory plant extract on two types of candidiasis-C. glabrata and C. krusei-was evaluated and the obtained results showed that the chicory extract is effective on C. glabrata and C. krusei according to a two-directional result, but C. krusei's sensitivity to the chicory extract is more than the sensitivity of C. glabrata, as C. krusei's lack of growth halo diameter is more than that of $C$. glabrata, and the $C$. intybus growth preventive lowest concentration was lesser for C. krusei compared with C. glabrata.

Table 3: The antifungal sensitivity points evaluation in C. glabrata and C. krusei types in well diffusion method

\begin{tabular}{llll}
\hline & \multicolumn{3}{c}{ Well diffusion } \\
\cline { 2 - 4 } Candida type & $\begin{array}{l}\text { Sensitive } \\
(\mathrm{mm})\end{array}$ & $\begin{array}{l}\text { Sensitive depending } \\
\text { on the dose }(\mathrm{mm})\end{array}$ & $\begin{array}{l}\text { Resistance } \\
(\mathrm{mm})\end{array}$ \\
\hline Krusei candida & $24(>20)$ & $10-20$ & $<10$ \\
Glabrata candida & $14(>11)$ & 11 & $<10$ \\
\hline
\end{tabular}

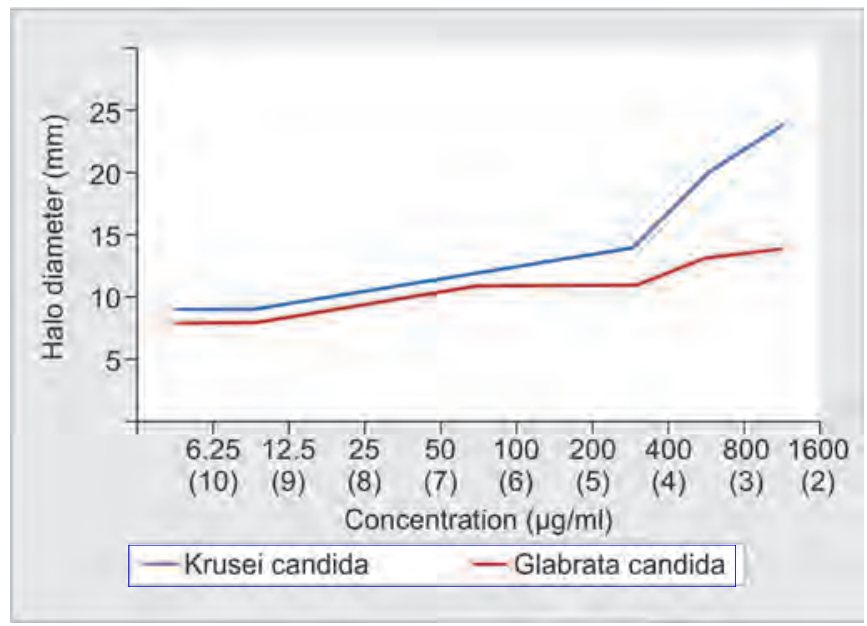

Graph 1: The comparison of chicory extract's antibacterial effect against C. krusei and C. glabrata

The widespread and long-run application of antibiotics, corticosteroids, and immunity-suppressing drugs, as well as basic illnesses such as diabetes and AIDS, etc., has caused an increase in the rate of fungal infection, especially C. glabrata and C. krusei, as compared with the past. ${ }^{3}$ On the contrary, in addition to the side effects of common antifungal drugs, the previous studies have proved the defeat of these antifungal drugs on different clinical infections of candidiasis and their medical resistance as the thiazole (like fluconazole) in long-run usage, especially in patients with deficiency of immunity system in two types of mentioned candidas (C. glabrata and C. krusei). ${ }^{1,2,23}$

In recent years, many studies have been performed; these evaluations have shown that some plants have the same effects as medical drugs or even more than them. One such plant is from the Asteraceae family and it is one of the compositions that has been considered in many studies and treatments in the medical field recently. ${ }^{6}$ Previous studies have shown that chicory extract has antibacterial, antimalarial, anti-inflammatory, painkiller, anticancer, antidiabetic, digestion, and liver protective 
effects. Some studies evaluated the antimicrobial effect of the chicory extract on the positive pathogen bacteria such as Bacillus subtilis, Staphylococcus aureus, and Micrococcus luteus and the Gram-negative pathogenic bacteria such as Escherichia coli and Salmonella typhi. ${ }^{13-15,24,25}$ The results of these studies proved that the chicory root extract has a stronger preventive effect on the Gram-positive bacteria compared with the Gram-negative types. Also, the chicory root extract hexane ethyl acetate has a stronger antibacterial effect compared with the chloroform extract and the watery extract of the chicory root.

The coffee-chicory's antibacterial effect on Streptococcus mutans that exists in the dental plaque has been evaluated, and the result of this study has shown that chicory has an antibacterial effect and coffee has an antiadhesive effect, leading to a reduction of bacteria for connecting to the surfaces and shaping biofilms. ${ }^{24}$

Furthermore, the antiviral features of the chicory extract on the adenovirus and subcategories of the herpes virus are specified. ${ }^{25}$ In contrast to the previous study results, Ghaderi et al's study in 2012 showed that the chicory extract does not have an antibacterial effect on the Gram-positive Streptococcus aureus, Streptococcus pyogenes, and Enterococci bacteria. ${ }^{26}$ The reason for this difference could be due to the following issues:

- The part of the chicory plant was used to prepare the extract: The previous study results have shown that different parts of the chicory plant such as the leaf, seed, root, and crust have antibacterial features, but the antibacterial features of the root and leaves in this plant are more than other parts. ${ }^{27}$ Studies have often used either the chicory $\operatorname{root}^{13,28}$ or the leaves ${ }^{27,28}$ to prepare the chicory extract. The root and leaf of the chicory plant have differences in their secondary components and these differences could be a reason for the differences in the extract's antibacterial effects and the results obtained from similar studies. ${ }^{29}$ In this study, the plant leaf was used to prepare the chicory extract.

- The chicory plant growing region type: This plant usually needs cool weather or sunny weather with some shade and it does not tolerate intensive heat. The secondary components of the various parts of the chicory plant can be different depending on the region that the plant was grown and even the time of the plant's harvest. ${ }^{30,31}$

- The type of solvent used for preparing the chicory extract: The type of solvent used could have an effect on the extract, causing different features to emerge. Based on the results obtained from previous studies, alcoholic solvents such as ethanol are more suitable than other solvents to prepare the chicory extract and it presents the chicory extract's antimicrobial features better than others. ${ }^{18,26,32}$
- Different concentrations based on the applied methods for the evaluation of the antimicrobial features of the chicory extract: There are different protocols for evaluating the antimicrobial features of drugs and extracts. The suggested method is different for each of them as per the CSLI protocol. These include different methods that are suggested according to the microorganisms or the drugs that are being evaluated, such as the agar well diffusion method and the determination of MIC through macrodilution. ${ }^{33}$

- The studying microorganism type and differences in the rate of their medical resistance: For example, there are different types of candidas and the medical resistance of common candidas is different in various conditions. ${ }^{34}$ Some of the previous studies have evaluated the chicory root extract's antifungal features and the results of these studies have shown that this extract has antifungal effects on Aspergillus niger, Saccharomyces cerevisiae, Pellicularia sasakii, and Alternaria kikuchiana funguses and that the antifungal effect of the chicory hexane extract on A. niger is approximately similar to that of S. cerevisiae. ${ }^{13,35}$

According to the performed studies, the secondary components in the chicory extract, especially in the sesquiterpene lactones such as lactucin and lactucopicrin, are responsible for the plant's antifungal effect. ${ }^{32,35,36}$

One of the most important studies is the Mares et $\mathrm{al}^{37}$ study that evaluated the chicory extract's effect on the phytopathogenic fungus (plant infecting fungus) and the dermatophyte (skin infecting fungus). The results of this study showed that the effect of this extract in preventing the dermatophyte fungus is more than the phytopathogenic fungus, and the main part of the chicory extract's antifungal activity is due to the presence of two main sesquiterpene lactone including deoxylactucin and $\beta, 13$-dihydrolactucin.

The results of previous studies proved that the acetone and ethyl acetate chicory extract in composition with the antibiotics could show synergism effects. ${ }^{38,39}$

Similar to the previous studies, the present research shows the antimicrobial and antifungal effects of the chicory extract; but in relation to the chicory extract's antifungal effects, previous studies were performed mainly on noncandidiasis funguses. Hence, in this study, we evaluated the extract's antifungal effects on C. glabrata and C. krusei as these are the types with more prevalence and medical resistance compared with the albicans type, especially in patients who suffer from immunosuppressive diseases. In the present research, to evaluate the extract's antifungal effects, the two methods of agar well diffusion and MIC were used based on the protocol determined by the CLSI. As per the CLSI, the results of both tests are the same and show a higher sensitivity of C. krusei toward the chicory extract compared with C. glabrata. 
According to the side effects, low cost of chicory extract, and the considerable effect of this extract on dermatophyte funguses, C. krusei and C. glabrata, and by regarding up to this point that most of the candidiasis infections involve the skin and oral mucosa, it is hoped that such extract will be substituted for chemical drugs in fungal infection treatment in future years. Of course, to generalize this concept, more widespread studies as clinical trials are inevitable. Furthermore, it is advised that the clinical trials are planned to evaluate the chicory extract antifungal effects in oral fungal infection treatments.

\section{CONCLUSION}

The results obtained from the present research have shown that the chicory extract has antifungal features. The results obtained from both the methods of agar well diffusion and the MIC as the macrodilution with the maximum preventive concentration proved that C. krusei has more microbial sensitivity compared with C. glabrata, regardless of microbial sensitivity of both funguses to the chicory extract.

\section{REFERENCES}

1. Geo B, Carrol KC, Butel J, Morse SA, Jawetz M. Adelberg's medical microbiology. 26th ed. New York: McGraw-Hill; 2013.

2. Neville BW, Damm DD. Oral and maxillofacial pathology. 3rd ed. St. Louis (MO): Elsevier; 2008.

3. Shaikh T, Rub RA, Sasikumar S. Antimicrobial screening of Cichorium intybus seed extracts. Arab J Chem 2012 Apr;34:111-119.

4. Mehmood N, Zubair M, Rizwan K, Rasool N, Shahid M, Ahmad VU. Antioxidant, antimicrobial and phytochemical analysis of Cichorium intybus seeds extract and various organic fractions. Iran J Pharm Res 2012 Autumn;11(4):1145-1151.

5. Wingard JR, Merz WG, Rinaldi MG, Johnson TR, Karp JE, Saral R. Increase in Candida krusei infection among patients with bone marrow transplantation and neutropenia treated prophylactically with fluconazole. N Engl J Med 1991 Oct;325(18):1274-1277.

6. Wu CD. Grape products and oral health. J Nutr 2009 Sep;139(9):1818S-1823S.

7. Street RA, Sidana J, Prinsloo G. Cichorium intybus: traditional uses, phytochemistry, pharmacology, and toxicology. Evid Based Complement Alternat Med 2013 Oct;2013:579319.

8. Loi M, Maxia L, Maxia A. Ethnobotanical comparison between the villages of Escolca and Lotzorai (Sardinia, Italy). J Herbs Spices Med Plants 2005; 11(3): 67-84.

9. Hazra B, Sarkar R, Bhattacharyya S, Roy P. Tumour inhibitory activity of chicory root extract against Ehrlich ascites carcinoma in mice. Fitoterapia 2002 Dec;73(7):730-733.

10. Behnam-Rassouli M, Aliakbarpour A, Hosseinzadeh H, Behnam-Rassouli F, Chamsaz M. Investigating the effect of aqueous extract of Chicorium intybus L. leaves on offspring sex ratio in rat. Phytother Res 2010 Sep;24(9):1417-1421.

11. Schmidt BM, Ilic N, Poulev A, Raskin I. Toxicological evaluation of a chicory root extract. Food Chem Toxicol 2007 Jul;45(7):1131-1139.
12. Olsen NJ, Branch VK, Jonnala G, Seskar M, Cooper M. Phase 1, placebo-controlled, dose escalation trial of chicory root extract in patients with osteoarthritis of the hip or knee. BMC Musculoskelet Disord 2010 Jul;11(1):156.

13. Koner A, Ghosh S, Roy P. Isolation of antimicrobial compounds from chicory (Cichorium intybus L.) root. Int J Res Pure Appl Microbiol 2011 Aug;1(2):13-18.

14. Nandagopal S, Kumari BDR. Phytochemical and antibacterial studies of chicory (Cichorium intybus L.)-A multipurpose medicinal plant. Adv Biol Res 2007 Jan;1(1-2):17-21.

15. Petrovic J, Stanojkovic A, Comic LJ, Curcic S. Antibacterial activity of Cichorium intybus. Fitoterapia 2004 Dec;75(7-8): 737-739.

16. Schwalbe R, Steele-Moore L, Goodwin AC. Antimicrobial susceptibility testing protocols. 1st ed. Boca Raton (FL): CRC Press; 2007.

17. Kashani H, Tabatabaei-Yazdi F, Mortazavi A, Shahidi F. Antifungal effect of aqueous and ethanolic extract of pinecone (Pinuselderica) of tehranon on Aspergillus niger and Candida albicans. Iran J Infect Dis Trop Med 2015; 20(69): 9-15.

18. Amjad A, Arbabian S, Kaviyani M. Evaluation of antimicrobial effects of underground and air organs and plant seeds of kasani (Cichoium intybus L) on the positive and negative gram bacterias. Q Biol Sci Zanjan Islamic Azad Univ 2009; 2(3): 13-21.

19. Mohammadi Q, Minae M, Somi M, Mosaddegh M, Kamalinejad M. Use of chicory (Cichorium intybus L.) root for the treatment of intractable hiccups. Tradit Integr Med 2016 Sep;1(2):66-68.

20. Salam R, Sarker BK, Haq MR, Khokon JU. Antimicrobial activity of medicinal plant for oral health and hygiene. Int J Nat Soc Sci 2015 Feb;2(1):1-12.

21. Pradhan B, Bhatt D, Mishra SK, Sahoo S. Antimicrobial potential of leaves of Adhatoda vasica nees. Against human pathogens causing infections of UT, GIT and Skin. Pharm Biol Eval 2015 Feb;2(1):36-39.

22. Magaldi S, Mata-Essayag S, de Capriles $\mathrm{CH}$, Perez C, Colella MT, Olaizola C, Ontiveros Y. Well diffusion for antifungal susceptibility testing. Int J Infect Dis 2004 Jan;8(1):39-45.

23. Chen TC, Chen YH, Chen YC, Lu PL. Fluconazole exposure rather than clonal spreading is correlated with the emergence of Candida glabrata with cross-resistance to triazole antifungal agents. Kaohsiung J Med Sci 2012 Jun;28(6):306-315.

24. Rehman Z, Daud M, Khan Afridi MQ, Bahadar S, Hayat A, Ali F, Hassan A, Rahman KU, Zeb A, Ahmad A, et al. Antimicrobial activity of Punica granatum and Cichorium intybus extracts against some pathogenic bacteria. Am Euras J Agric Environ Sci 2015 Jan;15(7):1265-1271.

25. Verma R, Rawat A, Ganie SA, Agnihotri RK, Sharma R, Mahajan S, Gupta A. In vitro antibacterial activity of Cichorium intybus against some pathogenic bacteria. Br J Pharm Res 2013 Oct-Dec;3(4):767-775.

26. Ghaderi R, Zardast M, Hosseini M, Delgir B, Hassanpour M. Comparison of antibacterial effect of Cichorium intybus L. with vancomycin, ceftriaxone, ciprofloxacin and penicillin (in vitro). Clin Exp Pharmacol 2012 Jun;2(2):1-3.

27. Sharma R, Reddy VK, Prashant GM, Ojha V, Kumar NP. Antimicrobial and anti-adherence activity of various combinations of coffee-chicory solutions on Streptococcus mutans: an in-vitro study. J Oral Maxillofac Pathol 2014 Sep;18(2):201-206.

28. Arikan S, Ostrosky-Zeichner L, Lozano-Chiu M, Paetznick V, Gordon D, Wallace T, Rex JH. In vitro activity of nystatin 
compared with those of liposomal nystatin, amphotericin B, and fluconazole against clinical Candida isolates. J Clin Microbiol 2002 Apr;40(4):1406-1412.

29. Jurgoński A, Milala J, Juśkiewicz J, Zduńczyk Z, Król B. Composition of chicory root, peel, seed and leaf ethanol extracts and biological properties of their non-inulin fractions. Food Technol Biotechnol 2011 Jan;49(1):40-47.

30. Amaducci S, Pritoni G. Effect of harvest date and cultivar on Cichorium intybus yield components in north Italy. Ind Crops Prod 1998 Jan;7(2):345-349.

31. Baert JR. The effect of sowing and harvest date and cultivar on inulin yield and composition of chicory (Cichorium intybus L.) roots. Ind Crops Prod 1997 Aug;6(3):195-199.

32. Zaman R, Basar SN. A review article of Beekhe Kasni (Cichorium intybus) its traditional uses and pharmacological actions. Res J Pharm Sci 2013 Sep;2(8):1-4.

33. KarimiMH,EbrahimnezhadS,NamayandehM,AmirghofranZ. The effects of Cichorium intybus extract on the maturation and activity of dendritic cells. Daru 2014 Feb;22(1):28.
34. Zaferani ZH, Bayat M, Mohammadi SR. Evaluating the adherence of fluconazole resistant Candida albicans species in comparison with Candida glabrata species on Vagina and intestine cell lines. NCMBJ 2015 Mar;5(17):74-80.

35. Nishimura H, Kondo Y, Nagasaka T, Satoh A. Allelochemicals in chicory and utilization in processed foods. J Chem Ecol 2000 Sep;26(9):2233-2241.

36. Shaikh T, Mujum A, Wasimuzzama K, Rub RA. An overview on phytochemical and pharmacological profile of Cichorium intybus Linn. Pharmacologyonline 2010;2:298-307.

37. Mares D, Romagnoli C, Tosi B, Andreotti E, Chillemi G, Poli F. Chicory extracts from Cichorium intybus L. as potential antifungals. Mycopathologia 2005 Aug;160(1):85-91.

38. Aqil F, Ahmad I. Antibacterial properties of traditionally used Indian medicinal plants. Methods Find Exp Clin Pharmacol 2007 Mar;29(2):79-92.

39. Stefanović OD, Stanojević DD, Comić LR. Synergistic antibacterial activity of Salvia officinalis and Cichorium intybus extracts and antibiotics. Acta Pol Pharm 2012 May-Jun;69(3):457-463. 